\title{
The Initiation of Dry Patches in Cloud-Resolving Convective Self-Aggregation Simulations: Boundary Layer Dry-Subsidence Feedback
}

\author{
BOLEI YANG ${ }^{\mathrm{a}}$ AND ZHE-MIN TAN ${ }^{\mathrm{a}}$ \\ ${ }^{\text {a }}$ School of Atmospheric Sciences, Nanjing University, Nanjing, China
}

(Manuscript received 7 May 2020, in final form 20 September 2020)

\begin{abstract}
Self-aggregation of convection can be considered as the simultaneous occurrence of dry patch initiation/amplification and wet patch contraction/intensification from initially uniform moisture and temperature fields. As the twin of wet patches, dry patches play an important role in moisture and energy balance during convective self-aggregation. In this study, the WRF Model is used to study the initiation of dry patches in convective self-aggregation, especially the continuous drying in their boundary layer (BL). In the dry patch BL, increased air density leads to an enhanced high pressure anomaly, which drives an amplifying BL divergent flow and induces an amplifying BL subsidence. The virtual effect of drying by subsidence counteracts warming by subsidence and the BL process, further increasing BL air density. Our analysis indicates the existence of a drysubsidence feedback, which leads to the initiation of dry patches in convective self-aggregation. This feedback is shown to be important even in very large-scale $(3000 \mathrm{~km} \times 9000 \mathrm{~km})$ cloud-resolving convective self-aggregation simulations.
\end{abstract}

KEYWORDS: Convection; Dynamics

\section{Introduction}

Aggregated convection can often be observed in the tropics (e.g., Houze and Betts 1981; Tobin et al. 2012; Stein et al. 2017). Studies show that along with the aggregation of convection, largescale temperature and water vapor can be altered (e.g., Bretherton et al. 2005; Muller and Held 2012). Understanding the organization of convection may deepen our understanding of tropical weather and climate. Intuitively, the aggregation tendency of convection could be influenced by large-scale forcing, such as sea surface temperature gradient and vertical wind shear (e.g., Tompkins 2001). However, without large-scale forcing, convection can still spontaneously organize from a uniform radiative-convective equilibrium (RCE) initial background (e.g., Held et al. 1993; Tompkins and Craig 1998; Grabowski and Moncrieff 2001; Bretherton et al. 2005; Muller and Held 2012; Wing and Emanuel 2014). This phenomenon is referred to as convective self-aggregation.

In fact, there is no long-lasting convective element in convective self-aggregation, rather it is actually the expansion/contraction of regions that are favorable or unfavorable for convective activity. So the key to understanding convective self-aggregation is to understand the interactions between convective and nonconvective regions. In convective self-aggregation, convective clusters are surrounded by nonprecipitating areas with steadystate subsidence, areas usually known as dry patches. Dry patches are often treated as the dry equilibria of radiative-convective equilibrium (e.g., Sobel et al. 2007; Sessions et al. 2015) and could result from radiative-convective instability (Emanuel et al. 2014; Beucler and Cronin 2016; Beucler et al. 2018). As the twin of wet patches in convective self-aggregation, dry patches are important for whole domain moisture and energy balance. When convective regions become wetter, their local surface latent heat flux generally becomes smaller, due to smaller air-sea moisture disequilibrium

Corresponding author: Zhe-Min Tan,zmtan@nju.edu.cn (even with enhanced convective gustiness in the convective region). In contrast, there is a large amount of moisture entering the boundary layer (BL) of dry patches, and only with moisture supply from dry patches can wet patches continuously become wetter. Conversely, the huge amount of latent heat released in the convective region cannot be locally removed, due to thick cloud. To maintain energy balance, heat must be transported to the dry patches then radiate out to space (Wing et al. 2017).

Generally, dry patches getting drier is more obvious at the early stage of convective self-aggregation when sea surface temperature (SST) is not very high (e.g., Bretherton et al. 2005; Muller and Held 2012; Jeevanjee and Romps 2013; Wing and Emanuel 2014; Coppin and Bony 2015; Tompkins and Semie 2017; Wing et al. 2017), although a few studies also show that dry and wet patches can intensify at the same time (e.g., Holloway and Woolnough 2016). Nonprecipitating dry patches often form in a few days, then intensify (i.e., become drier) and expand, finally driving the remaining convection into isolated clusters. The occurrence of dry patches is often treated as the trademark of convective selfaggregation. The priority of the formation of dry patches during convective self-aggregation indicates that there is strong positive feedback in dry patches, especially during the early period of convective self-aggregation. Bretherton et al. (2005) first mentioned the importance of anomalous longwave radiative cooling in dry patches. Using a frozen moist static energy (FMSE) analysis, Wing and Emanuel (2014) quantitatively showed the importance of longwave radiative feedback. Actually, as long as low-level radiative cooling anomaly in dry patches is sufficiently strong, convective self-aggregation will occur (Muller and Held 2012; Muller and Bony 2015). From a dynamics perspective, this lowlevel longwave cooling anomaly is responsible for an upgradient low-level secondary circulation, which favors convective selfaggregation by exporting FMSE from dry patches and importing FMSE into wet patches (Bretherton et al. 2005, Muller and Held 2012; Muller and Bony 2015). Coppin and Bony (2015) even 
described dry patches as "radiatively driven cold pools." Other feedbacks like shortwave radiative feedback and surface flux feedback are not that critical compared with longwave radiative feedback. Neither homogenizing shortwave radiative warming nor surface flux is very efficient in halting the formation of dry patches (Muller and Held 2012).

Although many mechanisms have been revealed, the initiation of dry patches is still unclear. Previous studies show that drying tendency in dry patches often begins in the upper troposphere (Wing and Emanuel 2014; Tompkins and Semie 2017). However, the dry anomaly in the upper troposphere is quite vulnerable and can be easily destroyed by deep convection. Dry patches cannot survive until their BL becomes too dry to support convection, so $\mathrm{BL}$ drying is critical to dry patch formation. From the perspective of available potential energy (APE) production, Yang (2018b) pointed out that diabatic processes and the virtual effect in the BL are critical to convective self-aggregation. However, the APE is just the energy reservoir for dynamics. His work could not show us how diabatic processes and the virtual effect may export moisture away and intensify certain dry patches. In this study, we generalize the physical mechanisms proposed in Yang (2018b) to threedimensional cloud-resolving simulations but focus on the drying of dry patch BL in the early stage of convective self-aggregation.

The simulation setup is introduced in section 2, and section 3 covers a comparison between our simulation and previous studies. The mechanisms for dry patch initiation are proposed in section 4 , and discussion about the mechanisms and some sensitivity experiments are covered in section 5. Conclusions are made in section 6 .

\section{Numerical model and experimental design}

The numerical model we use is the Weather Research and Forecasting (WRF) Model, version 3.7 (Skamarock et al. 2008), which has rarely been tested in convective self-aggregation studies. The idealized RCE setup of WRF is used, and to resolve convection while keeping the computational cost low, the horizontal gird spacing we choose is $3 \mathrm{~km}$ (it is often from 2 to $4 \mathrm{~km}$; e.g., Muller and Held 2012). There are 50 vertical levels in our domain among which 10 levels are below $1 \mathrm{~km}$ altitude. The first grid level is at $38 \mathrm{~m}$ above the ground, and the model top is at $27 \mathrm{~km}$ with the upper third of the model domain being a sponge layer. All simulations are three-dimensional on a square with double periodic boundary conditions. The sea surface temperature is fixed at $302.15 \mathrm{~K}\left(29^{\circ} \mathrm{C}\right)$ and the surface pressure set at $1000 \mathrm{hPa}$. There is no background wind, and the Coriolis parameter is set to zero. In all simulations, the Thompson microphysics scheme (Thompson et al. 2004), RRTMG longwave and RRTMG shortwave radiation scheme is used (Iacono et al. 2008). The solar radiation is fixed by setting the zenith angle and input solar radiation at $45^{\circ}$ and $500 \mathrm{~W} \mathrm{~m}^{-2}$, respectively. The YSU $\mathrm{BL}$ scheme is used, coupled with the revised Monin-Obukhov surface-layer scheme (Hong et al. 2006). The minimum surface wind speed in bulk surface flux parameterization is $0.1 \mathrm{~m} \mathrm{~s}^{-1}$.

We first perform an RCE simulation in a $90 \mathrm{~km} \times 90 \mathrm{~km}$ small domain for 100 days. Because of the domain limit, convective selfaggregation is not permitted in this simulation. The potential temperature and water vapor mixing ratio over the last 20 days are averaged to make an RCE profile. This profile is then horizontally homogenized in a much larger domain $(90 \mathrm{~km} \times 90 \mathrm{~km})$ to initialize the control experiment (CNTL) for convective selfaggregation. In both simulations, the convection is initiated by adding random noise in the potential temperature at the lowest 10 grid levels with maximum perturbation of $0.1 \mathrm{~K}$. The CNTL is run for 100 days with output every $3 \mathrm{~h}$.

\section{Convective self-aggregation in WRF: An overview}

Since few studies show convective self-aggregation in WRF natural run simulation (e.g., Tompkins and Semie 2017; Colin et al. 2019), we first discuss the characteristics of convective self-aggregation in our simulation and compare them with previous studies.

In previous studies, dry regions are defined as areas with a negative column accumulated FMSE anomaly (e.g., Wing and Emanuel 2014). The FMSE $(h)$ is given as follows:

$$
h=c_{p} T+g z+L_{v} q_{v}+L_{f} q_{i},
$$

where $T$ is temperature, $z$ is altitude, $q_{v}$ is the water vapor mixing ratio, $q_{i}$ is the ice mixing ratio, $c_{p}$ is the isobaric specific heat of dry air, $g$ is gravitational acceleration, and $L_{v}$ and $L_{f}$ are the latent heat of vaporization and freezing, respectively. FMSE is nearly conserved during moist adiabatic processes, even with the freezing and melting of precipitation. Convection only redistributes FMSE, it will not change the mass-weighted vertical integral. In our study, for any variable $X$, the horizontal mean of $X$ is denoted as $[X]$, the anomaly from the mean is denoted as $X^{\prime}=X-[X]$ and the density-weighted column sum of $X$ is denoted as $\hat{X}$.

Defining the dry patches with $\widehat{h}^{\prime}<0$ makes it easy to conduct FMSE budget analysis (which will be introduced in the following text). However, during the early stage of convective selfaggregation, areas with $\widehat{h}^{\prime}<0$ are not always nonprecipitating. Many areas have a dry bias for only a short time but will imminently have convective activity and precipitation. If these areas are treated as dry patches, the analysis will be contaminated. Dry patches must keep their drying nature for a period of time. In the present study, a grid point is defined to be in a dry patch when the accumulated precipitation is less than $0.1 \mathrm{~mm}$ in the following $48 \mathrm{~h}$. Figure 1 shows the time evolution of daily mean water vapor path (WVP) and dry patches during convective self-aggregation in CNTL. Discernable dry patches start to appear in the domain after about 8 days (Fig. 1a), and from day 10 to 14 (Figs. 1b,c), they dramatically intensify. Three obvious dry, and two weak dry patches remain at the end of day 14, and the WVP in the driest column of the dry patches declines to less than $20 \mathrm{~kg} \mathrm{~m}^{-2}$. After day 14 , these dry patches start to merge and expand. Only two dry patches remain at the end of day 30 (Fig. 1d), and they eventually merge into a bigger and stronger patch during the next 15 days (Fig. 1e). Although the remaining dry patch expands drastically, the WVP in its driest column never drops to less than $10 \mathrm{~kg} \mathrm{~m}^{-2}$. This dry patch continues to expand and finally drives the remaining wet patch into a cluster with very high WVP. After day 70, the dry patch expansion ceases and the system reaches a new equilibrium (Fig. 1f). Generally, dry patch development can be separated into two stages. Stage 1 is from day 1 to about day 14, during which dry patch intensification is dominant, and from day 14 to 70 , in stage 2 , dry patch expansion and merging dominates. Dry patch behavior 

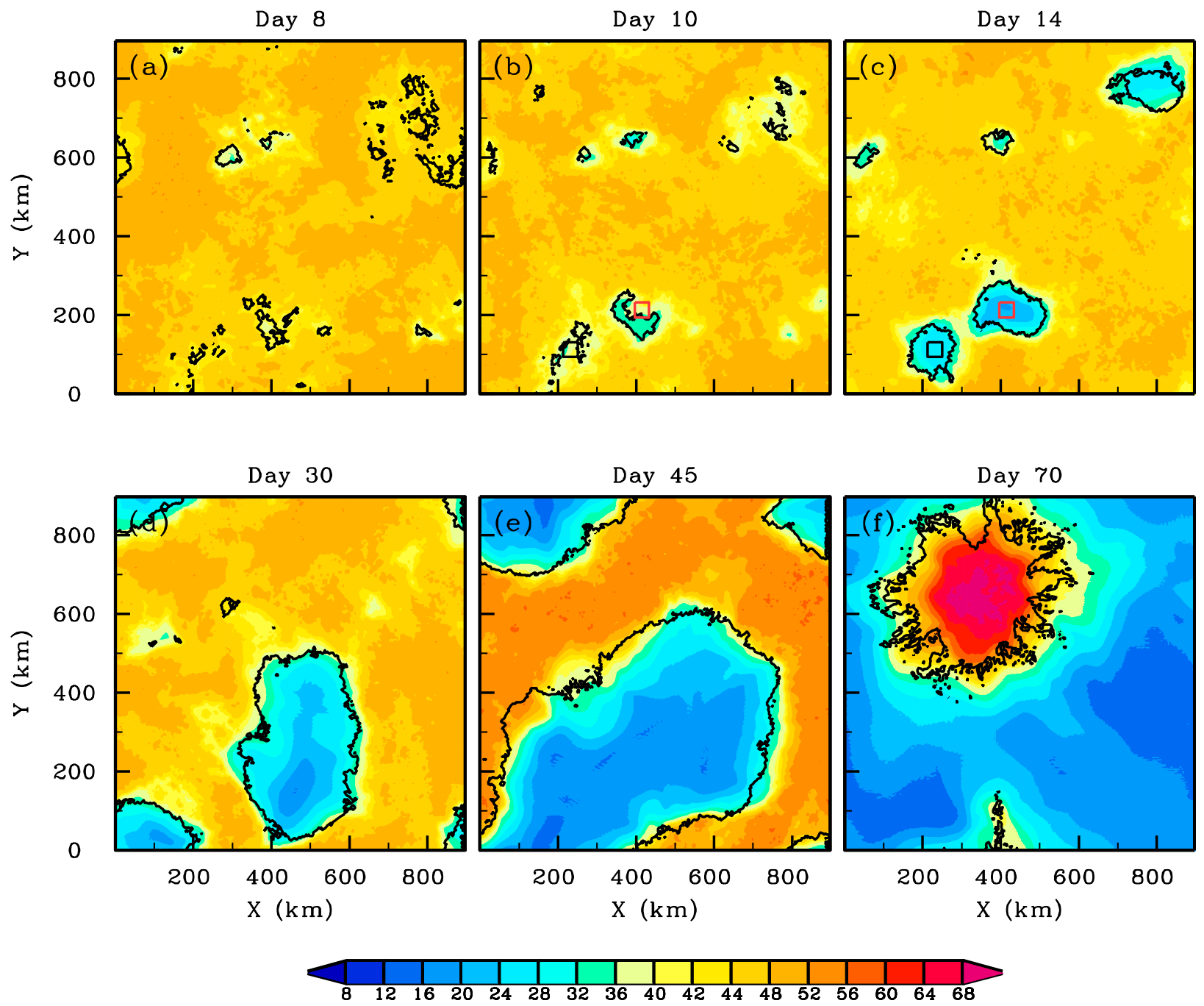

FIG. 1. Daily mean water vapor path $\left(\mathrm{kg} \mathrm{m}^{-2}\right)$ for days (a) 8 , (b) 10, (c) 14, (d) 30, (e) 45, and (f) 70 in CNTL. Dry patches are marked with black contours. The squares in (b) and (c) represent the formation of two dry patches.

in our simulation is quite similar to SAM results (e.g., Bretherton et al. 2005; Muller and Held 2012; Wing and Emanuel 2014).

Figure 2 shows the domain-averaged water vapor mixing ratio $q_{v}$ and temperature profiles averaged on day 1 and day 70 in CNTL. Similar to previous studies, especially above the BL (Fig. 2a), there is dramatic moisture loss in the whole domain, caused by the amplification and expansion of dry patches (e.g., Bretherton et al. 2005). Self-aggregation also features, with a domain-mean temperature increase of about $5 \mathrm{~K}$ in the lower troposphere, and about $10 \mathrm{~K}$ in the upper troposphere (Fig. 2b).

To test the feedbacks in convective self-aggregation in the present simulation, we conduct an FMSE budget analysis
(Wing and Emanuel 2014). The variance of $\hat{h}$ is defined as $\operatorname{Var}(\hat{h})=\left[\widehat{h}^{\prime 2}\right]$, and the equation of $\operatorname{Var}(\hat{h})$ expressed as

$$
\partial\left[{\hat{h^{\prime}}}^{\prime 2}\right] / \partial t=\left[2{\hat{h^{\prime}}}^{\prime} \mathrm{SEF}^{\prime}+2 \hat{h^{\prime}} \mathrm{NetSW}^{\prime}+2 \hat{h^{\prime}} \mathrm{NetLW}^{\prime}-2{\hat{h^{\prime}}}^{\prime} \cdot \mathbf{u} \hat{h}^{\prime}\right],
$$

where $\hat{h}^{\prime} \mathrm{SEF}^{\prime}, \hat{h^{\prime}} \mathrm{NetSW}^{\prime}$, and $\hat{h}^{\prime} \mathrm{NetLW}^{\prime}$ represent the contributions from surface flux, shortwave radiation, and longwave radiation, respectively; $-\hat{h}^{\prime} \nabla_{h} \cdot \mathbf{u} \hat{h}^{\prime}$ is the contribution from FMSE flux divergence, which is calculated as a residual from the remaining budget. The right-hand side of (2) can be further separated into contributions from the dry and the wet patches:

$$
\begin{aligned}
& \partial\left[{\widehat{h^{\prime}}}^{2}\right] / \partial t=\frac{1}{N} \sum_{\text {dry }}\left(2{\hat{h^{\prime}}}^{\prime} \mathrm{SEF}^{\prime}+2 \hat{h^{\prime}} \mathrm{NetSW}^{\prime}+2 \hat{h^{\prime}} \mathrm{NetLW}^{\prime}-2{\hat{h^{\prime}}} \nabla_{h} \cdot \mathbf{u} \hat{h}^{\prime}\right) \\
& +\frac{1}{N} \sum_{\mathrm{wet}}\left(2{\hat{h^{\prime}}}^{\mathrm{SEF}}+2{\hat{h^{\prime}}}^{\mathrm{NetSWW}}+2{\hat{h^{\prime}}}^{\prime} \mathrm{NetLW}^{\prime}-2{\hat{h^{\prime}}}^{\nabla_{h}} \cdot \mathbf{u} \hat{h}^{\prime}\right) .
\end{aligned}
$$



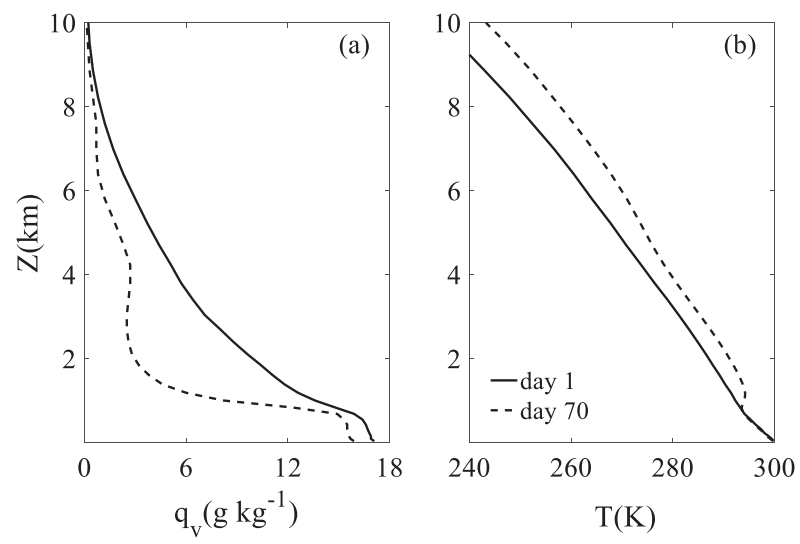

FIG. 2. Vertical profiles of daily and domain-averaged (a) water vapor mixing ratio $\left(\mathrm{g} \mathrm{kg}^{-1}\right)$ and (b) temperature $(\mathrm{K})$ on days 1 (solid) and 70 (dashed) in CNTL.

In Eq. (3), $N$ is the total grid number in the model domain.

The first term on the right-hand side of (3) represents contributions from dry patch processes, while the second term represents those in the wet patches. The domain averaged 2-day running-mean evolution of each term on the right-hand side of (3), which has been normalized by $\left[\hat{h}^{\prime 2}\right]$, is shown in Fig. 3a (all the terms referred to in the following context are normalized by $\left.\left[\hat{h}^{2}\right]\right)$. Among all the terms, longwave radiation has a positive contribution during the whole convective self-aggregation, especially in the early period, while shortwave radiation has very little contribution. Surface flux term contributes positively to $\operatorname{Var}(\hat{h})$ initially but contributes negatively in the later stage. The flux divergence term contribution is quite negative at the beginning but is close to zero during the later stage. Compared to Wing and Emanuel (2014), longwave radiation has a larger positive contribution in our simulation, while our flux divergence term has a larger negative contribution. Furthermore, the positive contribution from the flux divergence term during the intermediate stage in their study is not very obvious in ours, although the general results of both studies are similar.

For both dry and wet patches, longwave radiation has a positive contribution (Figs. $3 b, c$ ). This is because wet patches radiate less energy into space compared with dry patches, due to the thick cloud in wet patches. In the first 35 days, the surface flux term in wet patches contributes positively due to the large amount of latent heat flux produced by the strong gust front of cold pools in the wet patches (Fig. 3c; Wing and Emanuel 2014). After day 35, the dry patches get drier and larger, and surface flux in the wet patches becomes lower than in the dry patches, leading to a negative contribution of surface flux in the wet patches. In the dry patches after about 10 days, surface flux contributes negatively, because dry patch formation and intensification lead to an increase in surface moisture flux (Fig. 3b). The most obvious difference between the dry and wet patches is the flux divergence term. The flux divergence term in the dry patches almost always contributes positively to an increase in FMSE variance, indicating that there is a net FMSE export (Fig. 3b). The effect of the flux
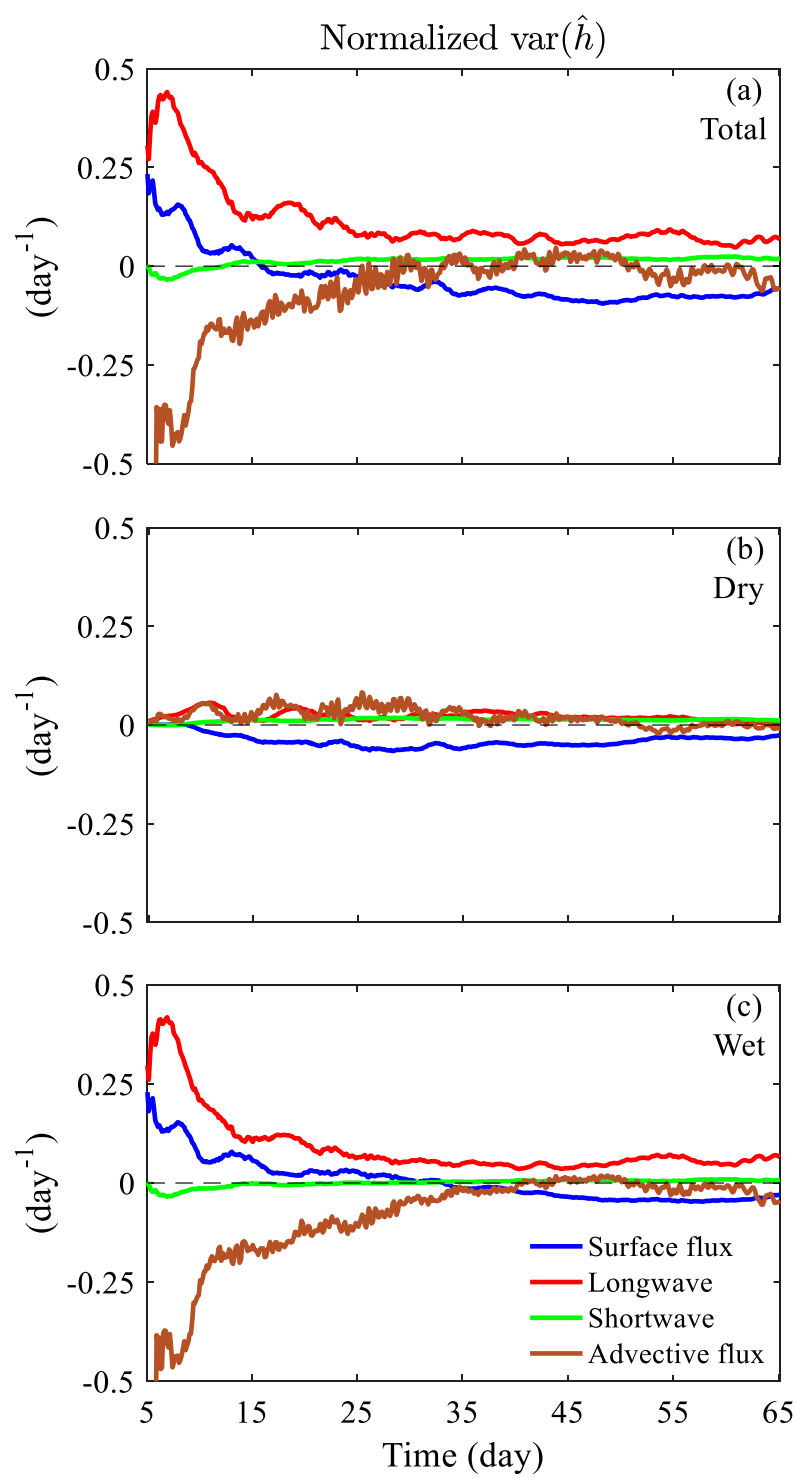

FIG. 3. (a) Time evolutions of domain averaged 2-day running-mean contributions of terms on the right-hand side of Eq. (3), including surface flux (blue), longwave radiation (red), shortwave radiation (green), and advective flux (brown); each term is normalized by $\left[\hat{h}^{\prime 2}\right]$, with a unit of day ${ }^{-1}$. (b),(c) As in (a), but from dry patches and wet patches, respectively.

divergence term in the dry patch is as important as the longwave radiation. Conversely, the flux divergence term in the wet patches has a large negative contribution initially, but gradually approaches zero during the later stage (Fig. 3c). The contribution of flux divergence in the whole domain is dominated by the flux divergence in the wet patches. Generally, the WRF Model can reproduce convective selfaggregation, with a domain-average drying and warming during the simulation, which is very similar to SAM results. The feedbacks revealed by FMSE budget analysis also show similar results with previous studies. 


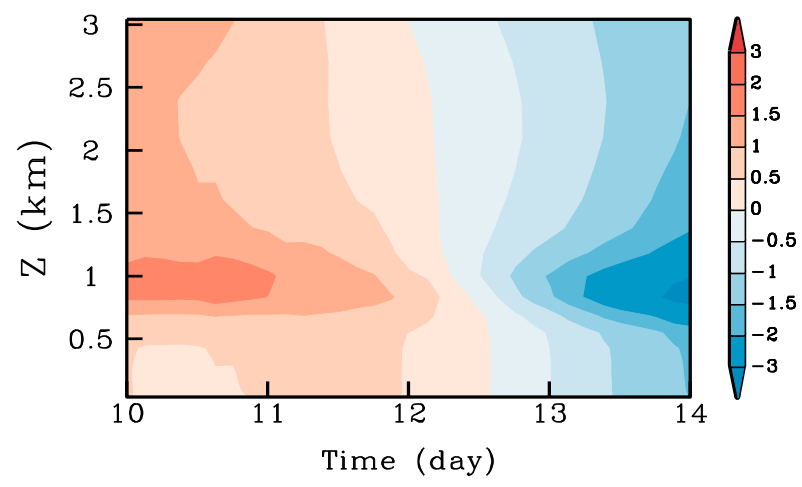

FIG. 4. Time evolution (24-h running mean) of water vapor $q_{v}$ $\left(\mathrm{g} \mathrm{kg}^{-1}\right)$, which is the anomaly from the day $10-14$ mean profile in the black square shown in Fig. 1.

\section{Mechanisms of dry patch formation}

Three dry patches in the domain experienced drastic intensification from day 10 to day 14 (Figs. 1b,c). Since two of the dry patches [with location $(249,120 \mathrm{~km})$ and (423, $216 \mathrm{~km}$ )] are almost stationary during this period, we choose to use an Eulerian perspective to study their development. By Eulerian, here it means the analysis that we conduct is over a spatially fixed area. Two spatially fixed squares in Figs. $1 \mathrm{~b}$ and $1 \mathrm{c}(30 \mathrm{~km} \times 30 \mathrm{~km})$ experience extreme drying from day 10 to 14 , so we choose them as examples to represent dry patch development. Since the processes in the two squares are very similar (not shown), we focus only on the processes in the black square. All the results in the following analysis are horizontally averaged in this square. The black square experiences continuous drying from day 10 to 14 , with a decrease of more than $18 \mathrm{~kg} \mathrm{~m}^{-2}$ in WVP (Fig. 1). The time evolution of water vapor mixing ratio $q_{v}$ profile in this square (24-h running mean), which is an anomaly from the day 10-14 mean profile, is shown in Fig. 4. There is a decrease of $q_{v}$ above the BL from day 10 to day 14, and the largest decrease is at about $1 \mathrm{~km}$ altitude, which is related to the decline of the BL top. In the BL, the decrease of $q_{v}$ is not obvious until day 12 , which is consistent with previous studies that drying tendency usually starts from upper levels (Wing and Emanuel 2014; Tompkins and Semie 2017). Due to the loss of water vapor, the convective available potential energy (CAPE) in this area decreases by about $1500 \mathrm{~J}$, and the convective inhibition (CIN) increases by about $100 \mathrm{~J}$, making convection difficult to initiate.

To find out the BL drying mechanism, a water vapor budget is conducted. The equation of $q_{v}$ can be written as follows:

$$
\frac{\partial q_{v}}{\partial t}=-\nabla_{h} \cdot\left(\mathbf{u} q_{v}\right)-\frac{\partial\left(w q_{v}\right)}{\partial z}+B_{q}+M_{q}+R_{q},
$$

where $-\nabla_{h} \cdot\left(\mathbf{u} q_{v}\right)$ and $-\partial\left(w q_{v}\right) / \partial z$ are the horizontal and vertical water vapor flux divergence terms, respectively; $B_{q}$ and $M_{q}$ represent contributions from BL parameterization and microphysics parameterization, respectively. All the above terms are WRF Model outputs. The last term, $R_{q}$, stands for the residual term, which includes the effect of high-order diffusion and some errors when reconstructing the variable from its mass-coupled flux form in the WRF Model.

The horizontal flux divergence term is negative in the $\mathrm{BL}$, while it becomes positive from the BL top to about $1.3 \mathrm{~km}$ altitude (Fig. 5a), indicating a net horizontal moisture export in the $\mathrm{BL}$ and a net horizontal moisture import right above it.
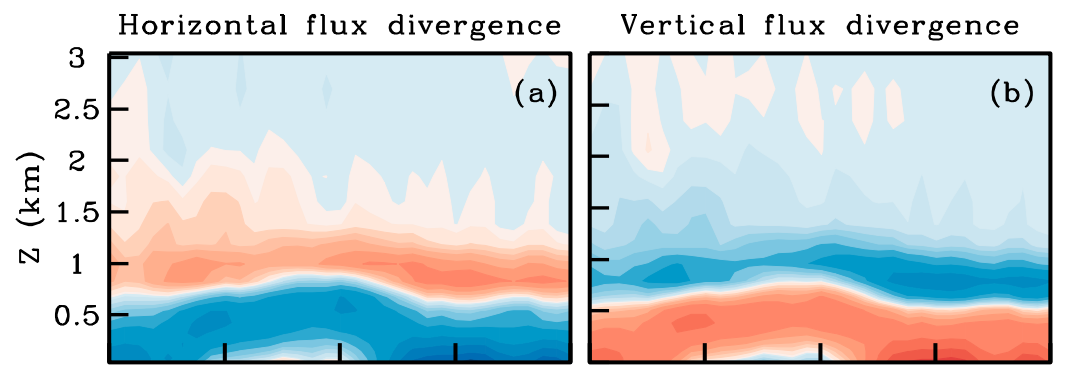

Total flux divergence
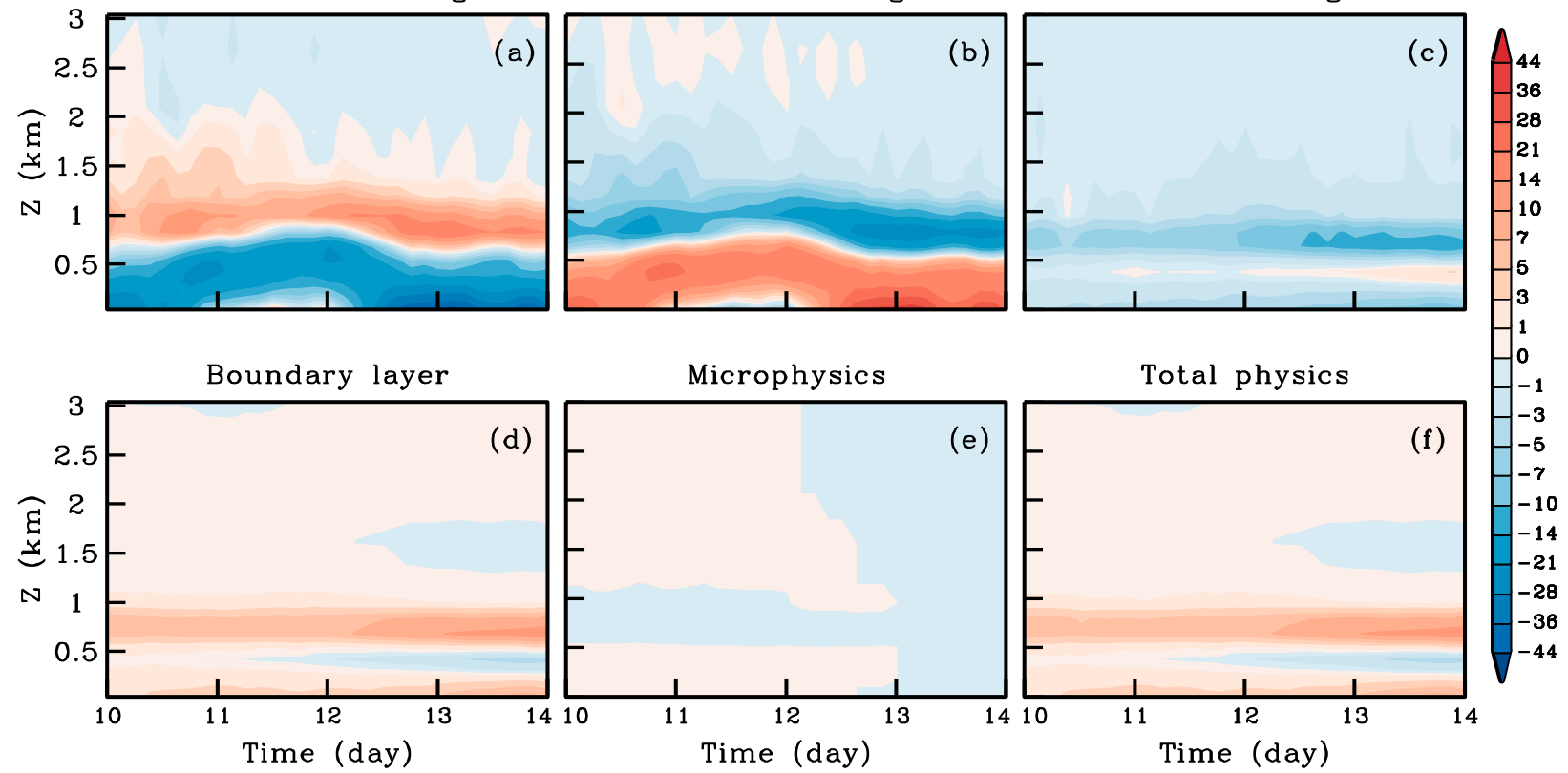

FIG. 5. Time evolution (24-h running mean) of $\partial q_{v} / \partial t\left(\mathrm{~g} \mathrm{~kg}^{-1} \mathrm{day}^{-1}\right)$ in the black square shown in Fig. 1 from day 10-14 due to (a) horizontal flux divergence; (b) vertical flux divergence; (c) total flux divergence: sum of (a) and (b); (d) boundary layer process; (e) microphysics process; and (f) total physics: sum of (d) and (e). 

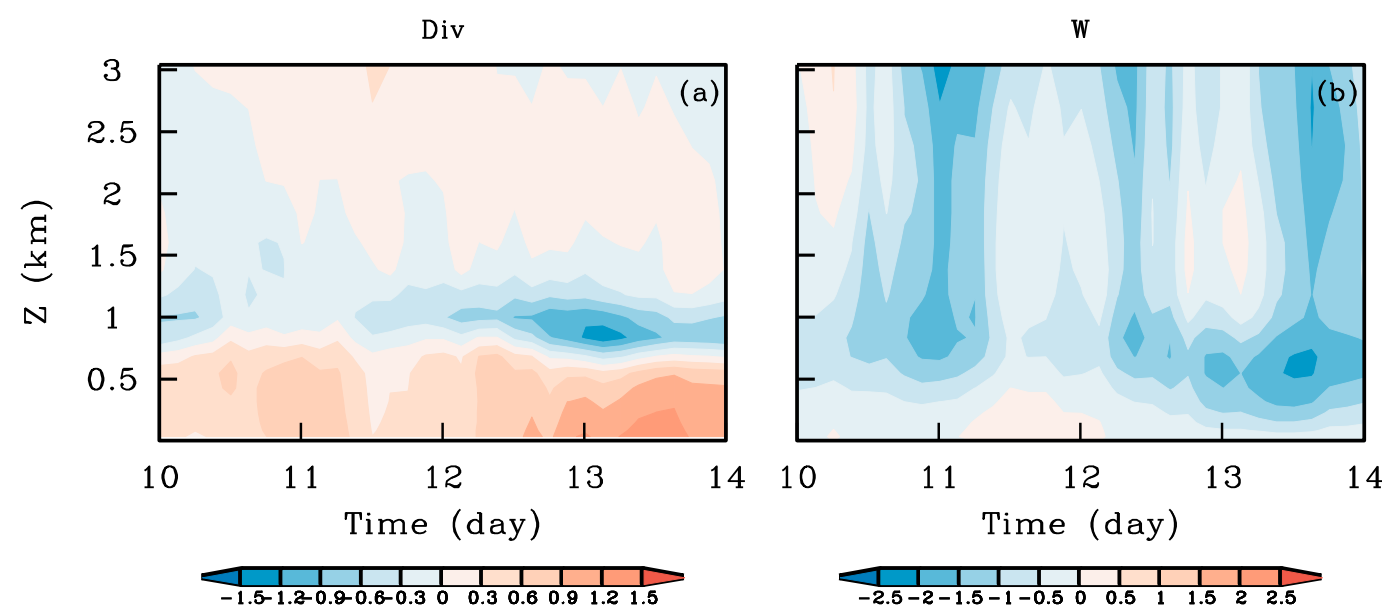

FIG. 6. Time evolution (24-h running mean) of (a) divergence $\left(\times 10^{-5} \mathrm{~s}^{-1}\right)$ and (b) vertical velocity $\left(\mathrm{cm} \mathrm{s}^{-1}\right)$ averaged in the black square shown in Fig. 1.

There is a divergence in the $\mathrm{BL}$ and a convergence right above the BL top, which corresponds very well with the horizontal flux divergence term (Fig. 6a). In the following analysis, the BL is defined as the divergence layer, which is from the surface to about $700 \mathrm{~m}$. The convergence layer right above the $\mathrm{BL}$ is also known as the return-flow layer (e.g., Naumann et al. 2017). The vertical flux divergence term has a similar magnitude with the horizontal flux divergence term, while the pattern is almost completely opposite (Fig. 5b). The negative vertical flux divergence term at the return-flow layer and the positive vertical flux divergence term in the $\mathrm{BL}$ indicate that moisture is transported from the return-flow layer into the BL, which is driven by subsidence. The time series of square-averaged vertical velocity (24-h running mean) is shown in Fig. 6b. From day 10 to 12 , descent prevails in the lower atmosphere, but there is still some weak ascent in the lower BL. After day 12, downward motion dominates the $\mathrm{BL}$ and intensifies with time. The patterns of the divergence and vertical velocity together imply the existence of a low-level secondary circulation (e.g., Bretherton et al. 2005; Muller and Held 2012), which intensifies during dry patch formation. The contribution of the total flux divergence (i.e., advection) term is shown in Fig. 5c. At the return-flow layer, moisture export by subsidence is larger than moisture import by horizontal convergence, leading to a strong drying tendency. In the BL, the air brought down by subsidence is less humid than the air exported by divergence, also resulting in a drying tendency. The total advective flux term generally shows a drying effect in the lower atmosphere, which intensifies during the analysis period (Fig. 5c). The BL process is connected with the surface flux, whose overall effect is to moisten the BL and the lower atmosphere (Fig. 5d). There is a weak drying band at $0.5 \mathrm{~km}$, which is due to dry air entrainment from the BL top (Fig. 5d). The weak moistening tendency by the total flux divergence term at $0.5 \mathrm{~km}$ is also related to the $\mathrm{BL}$ entrainment (Fig. 5c). Compared with other processes, microphysics process has very little contribution to the total moisture change (Fig. 5e). BL and microphysics are combined as the total physics process, which generally moisten the lower atmosphere (Fig. 5f). The residual term is two orders lower than for other processes, so it is ignored here.

Figure 7 shows the vertical profiles of each term on the righthand side of Eq. (4), averaged from day 10 to 14 . Generally, the

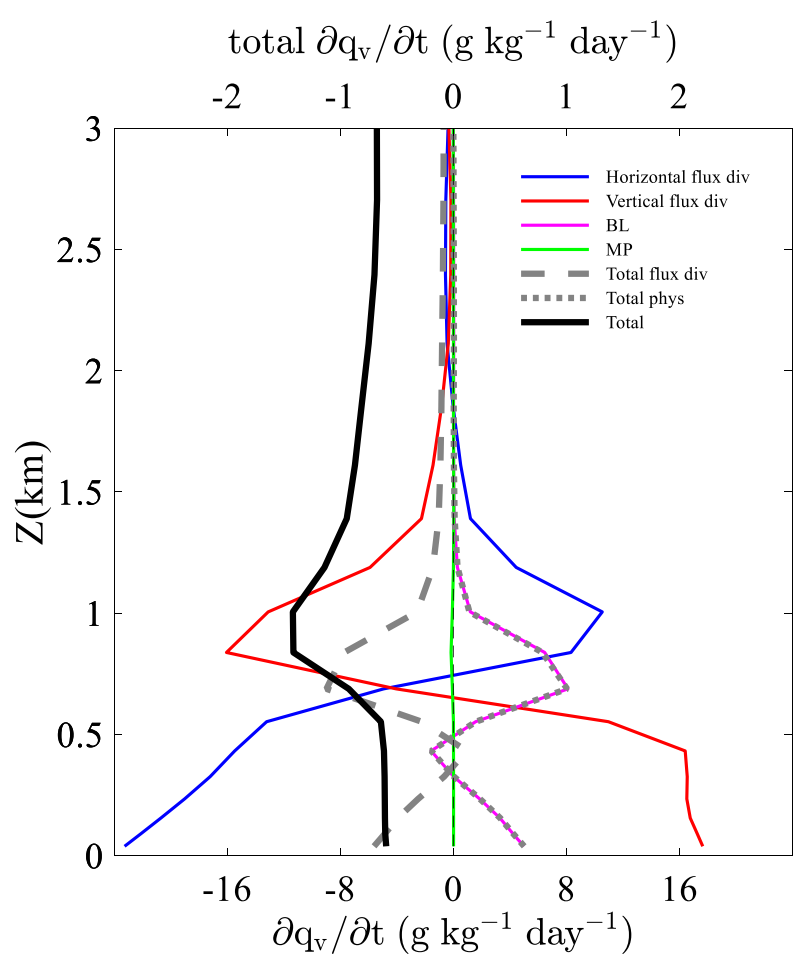

FIG. 7. Vertical profiles of area- and time-averaged (days 10-14) $\partial q_{v} / \partial t\left(\mathrm{~g} \mathrm{~kg}^{-1} \mathrm{day}^{-1}\right)$ in the black square shown in Fig. 1 due to horizontal flux divergence (blue solid), vertical flux divergence (red solid), boundary layer process (pink solid), microphysics process (green solid), total flux divergence (thick gray dashed), and total physics (thick gray dotted). The total water vapor mixing ratio change rate is shown by a thick black solid line, with a smaller-scale axis for this curve labeled along the top of the figure. 

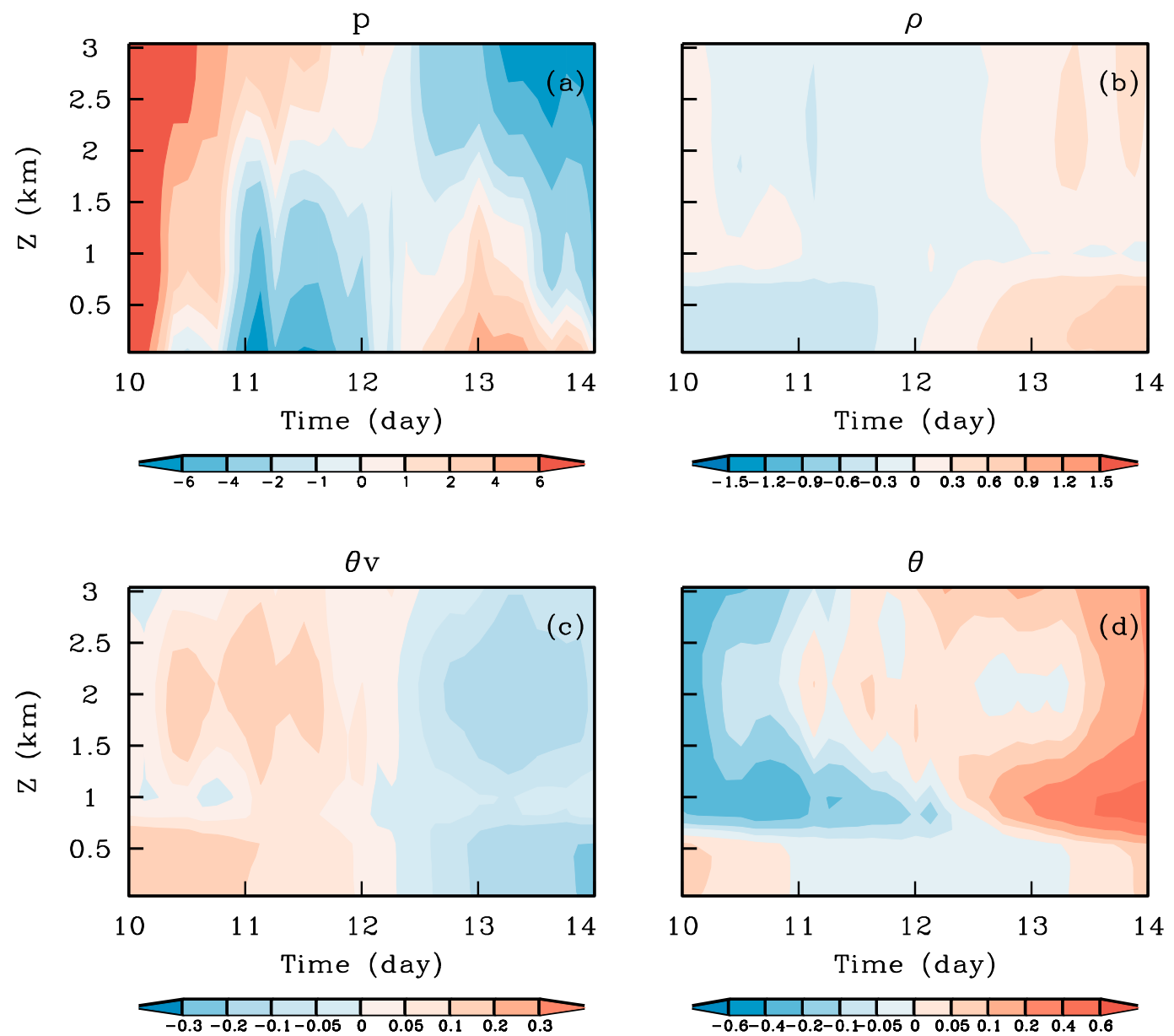

FIG. 8. (a) Time evolution (24-h running mean) of pressure (Pa) in the black square shown in Fig. 1, which is the anomaly from its day 10-14 mean profiles. (b)-(d) As in (a), but for density $\left(\times 10^{-3} \mathrm{~kg} \mathrm{~m}^{-3}\right)$, virtual potential temperature $\theta_{v}(\mathrm{~K})$, and potential temperature $\theta(\mathrm{K})$, respectively.

total advection term dries the dry patch atmosphere and matches the positive contribution of the flux divergence term (Fig. 3b). The total physics process (mostly resulting from the $\mathrm{BL}$ process) has a large moistening tendency in the BL. However, moistening by physics process is still small compared with drying by the advective flux term, finally resulting in a BL drying tendency.

From the above analysis, it is clear that the advection process, especially subsidence, is critical for drying in the dry patch BL. However, when the dry patch amplifies, the air-sea moisture disequilibrium becomes more significant, so more surface latent flux will enter the atmosphere and moisten the dry patch through the BL process (Fig. 5d). If subsidence does not intensify, water vapor supply by surface moisture flux will soon counteract drying by subsidence, and the dry patch will stop intensifying, and reach equilibrium. Therefore, for the dry patch to keep drying, subsidence in the BL must also continue to intensify. As shown in Fig. 6b, subsidence in the BL does intensify during the dry patch formation, especially after day 12. Understanding subsidence acceleration in the dry patch BL becomes the key to understanding dry patch intensification.
Dry patch BL usually corresponds to a high pressure anomaly, which will lead to a positive pressure gradient force, driving a divergence flow in the dry patch BL (e.g., Coppin and Bony 2015; Naumann et al. 2017; Arnold and Putman 2018). When the divergence in the BL intensifies, subsidence will also intensify due to mass continuity equation. Figure 8 a shows the time evolution of the pressure (24-h running mean) in the dry patch BL, which is the anomaly from the day 10-14 mean profile. There is an increasing pressure tendency in the dry patch BL, and a decreasing tendency of pressure above the BL. Under hydrostatic balance, the pressure at a certain height is the weight of air column above, and since the pressure above the BL decreases over time, a BL pressure increase can only result from an increase in BL air density (Fig. 8b).

Through the idealized gas law, the equation of density can be written as

$$
\rho=\frac{p\left(p / p_{0}\right)^{R_{d} / C_{p}}}{R_{d} \theta_{v}},
$$

in which $R_{d}$ is the dry air gas constant, $C_{p}$ is the specific heat at constant pressure, $p_{0}$ is a constant reference pressure, and $\theta_{v}$ is 

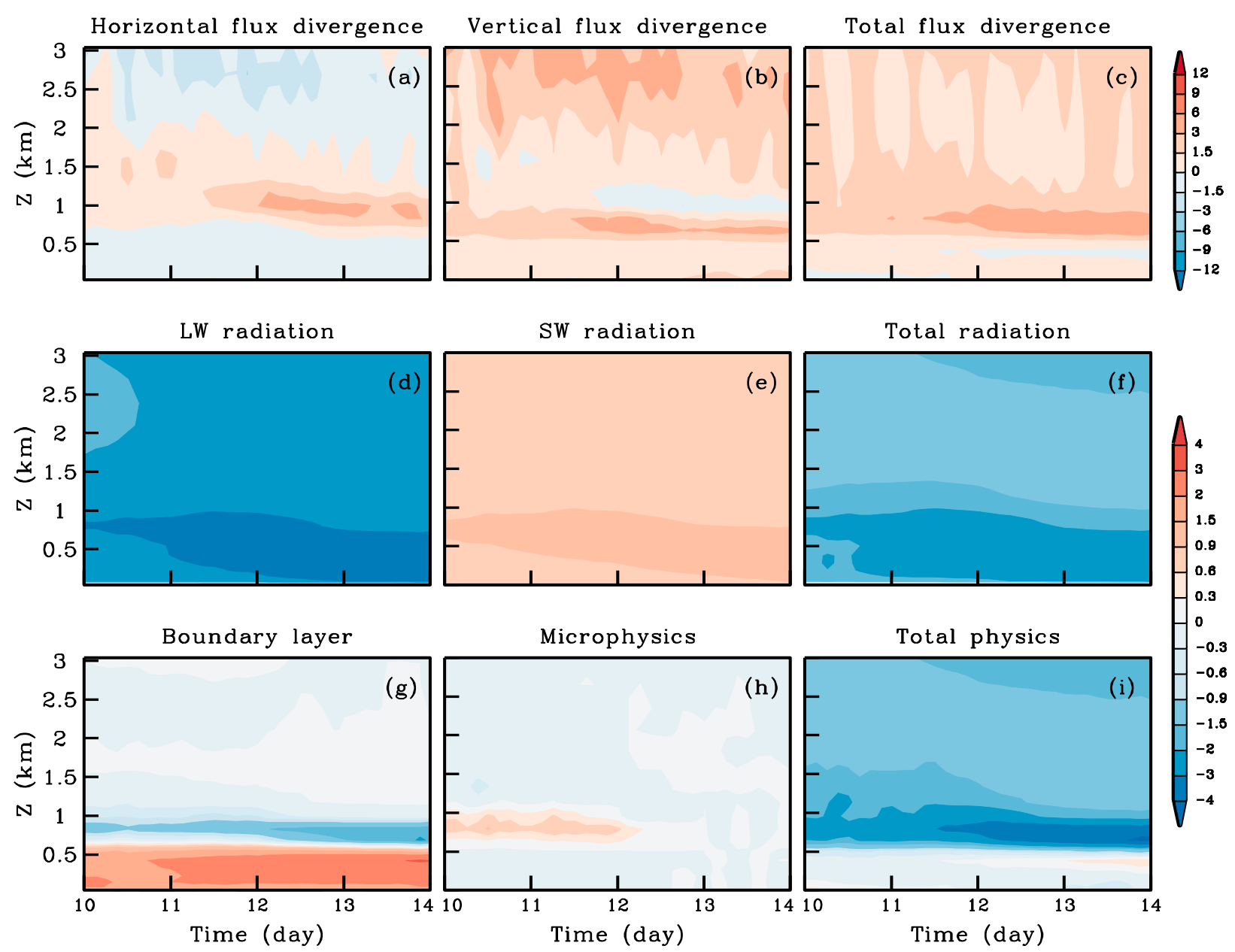

FIG. 9. Time evolutions (24-h running mean) of area-averaged $\partial \theta / \partial t\left(\mathrm{~K} \mathrm{day}^{-1}\right)$ in the black square shown in Fig. 1 due to (a) horizontal flux divergence; (b) vertical flux divergence; (c) total flux divergence: sum of (a) and (b); (d) longwave radiation; (e) shortwave radiation; (f) total radiation: sum of (d) and (e); (g) boundary layer process; (h) microphysics process; and (i) total physics: sum of (f)-(h). The upper color bar is for (a)-(c). The lower color bar is for (d)-(i).

virtual potential temperature. Equation (5) shows that both pressure increase and virtual potential temperature decrease will lead to density increase. Since BL air density is close to one, the value of the numerator and denominator on the right hand of Eq. (5) is very close. The pressure increase from day 10 to 14 is about $10 \mathrm{~Pa}$ (Fig. 8a). Assuming the original $\mathrm{BL}$ pressure is $1000 \mathrm{hPa}$, a $10 \mathrm{~Pa}$ pressure increase will lead to an increase in the numerator by about $12.8 \mathrm{~Pa}$. The evolution of $\theta_{v}$ is shown in Fig. 8c, which is also the anomaly from the day $10-14$ mean profile. The $\theta_{v}$ decrease in the dry patch $\mathrm{BL}$ is about $0.4 \mathrm{~K}$ from day 10 to 14 , which corresponds to a decrease in the denominator by $114.8 \mathrm{~m}^{2} \mathrm{~s}^{-2}$. Meanwhile, the pattern of $\theta_{v}$ change matches very well with density change, and therefore, the decrease of $\theta_{v}$ is mainly responsible for the increase in BL density.

The equation of $\theta_{v}$ can be written as

$$
\frac{\partial \theta_{v}}{\partial t}=\left(1+0.61 q_{v}\right) \frac{\partial \theta}{\partial t}+0.61 \theta \frac{\partial q_{v}}{\partial t} .
$$

Equation (6) shows that both potential temperature and water vapor change can affect $\theta_{v}$. Figure 8 d illustrates the time evolution of the potential temperature $\theta$, which is the anomaly from the day 10-14 mean profile. Potential temperature increases during this period, especially above the BL. The maximum increase is about $1 \mathrm{~K}$ at $1 \mathrm{~km}$ altitude, which is related to the decline of the BL top. In the BL, the potential temperature still shows a weak increasing tendency. Unlike the "radiatively driven cold pools" discussed in previous studies (Coppin and Bony 2015), dry patches in our simulation actually correspond to a warm BL anomaly (not shown).

To determine the reason for the warming, a potential temperature budget is constructed. The equation of $\theta$ can be written as

$$
\frac{\partial \theta}{\partial t}=-\nabla_{h} \cdot(\mathbf{u} \theta)-\frac{\partial(w \theta)}{\partial z}+\mathrm{LW}+\mathrm{SW}+B_{\theta}+M_{\theta}+R_{\theta}
$$

where $-\nabla_{h} \cdot(\mathbf{u} \theta)$ and $-\partial(w \theta) / \partial z$ are the horizontal and vertical flux divergence terms, LW and SW are contributions from 
longwave and shortwave radiation, $B_{\theta}$ represents contribution from the BL process and $M_{\theta}$ stands for contribution from microphysics process associated with water substance phase change. All the above terms are WRF Model outputs. The summation of radiation, BL, and microphysics terms are called the total physics term; $R_{\theta}$ represents the residual term.

The contributions from different terms to the potential temperature change are shown in Fig. 9. The total flux divergence term has a large warming effect above the BL, which strengthens over time (Fig. 9c), mainly due to contributions of the vertical flux divergence term (Fig. 9b). It is understandable because subsidence brings air with higher $\theta$ downward. In the $\mathrm{BL}$, warming by the total flux divergence term is weaker, because the positive contribution from vertical flux divergence term (Fig. 9b) is largely counteracted by the negative horizontal flux divergence term (Fig. 9a). It is noteworthy that there is a horizontal heat import at the return-flow layer (Fig. 9a). The vertical flux divergence term shows a negative contribution at the same altitude (Fig. 9b), indicating some heat brought by the return flow will be transported downward, and which may benefit BL warming. Longwave radiation cools the atmosphere. The maximum cooling stays at the BL top before day 12 and moves into the BL afterward, indicating a transition from low cloud radiative cooling to clear-sky radiative cooling (Fig. 9d). Shortwave radiation shows a warming tendency with a nearly opposite pattern to longwave radiation, but its magnitude is much smaller (Fig. 9e). The total radiative heating pattern is dominated by longwave radiation (Fig. 9f). The BL process warms the BL and cools the return-flow layer (Fig. 9g). Microphysics process warms in the cloud by water vapor condensation and cools the atmosphere both above and below the cloud layer by cloud water evaporation (Fig. 9h). The total diabatic process reveals a cooling tendency, especially at the return-flow layer (Fig. 9i). The residual term is two orders lower than for other processes, so it is ignored here.

Figure 10 shows vertical profiles of contributions to $\partial \theta / \partial t$, averaged from day 10 to 14 . The contribution from the total flux divergence (advection) has a positive tendency above the $\mathrm{BL}$, while the positive tendency becomes very weak in the BL. The contribution from total physics shows an almost opposite profile; however, the cooling by physics process is not strong enough to counteract advective warming, leading to a strong warming above, and a weak warming in the BL.

Besides potential temperature, the change of water vapor content will also affect $\theta_{v}$. With the same volume, temperature and pressure, a dry air parcel is heavier (denser) than a moist air parcel, which is known as the virtual effect. The drying tendency in the BL will favor density increase. The contributions to $\theta_{v}$ change from potential temperature [first term on the right-hand side of Eq. (6)] and water vapor [second term on the right-hand side of Eq. (6)] and are shown in Fig. 11. During the dry patch intensification, the decrease of $\theta_{v}$ by drying is greater than the increase by warming, finally leading to a $\theta_{v}$ decrease (density increase) below $1 \mathrm{~km}$.

A brief summary of dry patch formation is as follows. Over a time scale of several days, the dry patch formation is assumed under hydrostatic balance. At the beginning, the drying at upper levels leads to stronger BL longwave radiative cooling

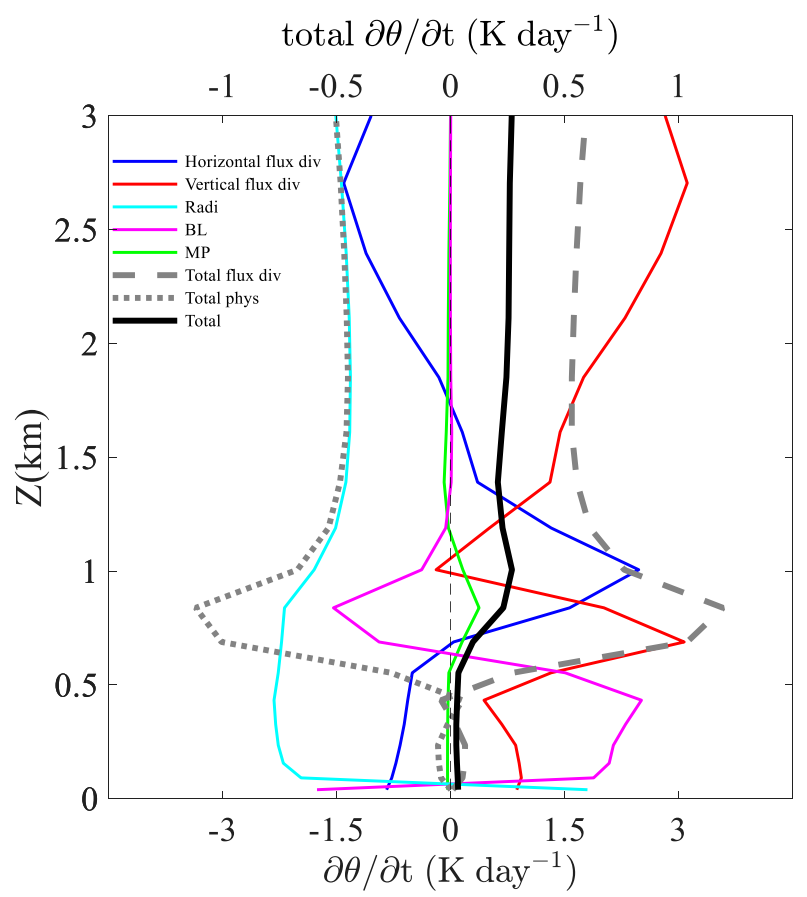

FIG. 10. Vertical profiles of area- and time-averaged (days 10-14) $\partial \theta / \partial t\left(\mathrm{~K} \mathrm{day}^{-1}\right)$ in the black square shown in Fig. 1 due to horizontal flux divergence (blue solid), vertical flux divergence (red solid), radiation (cyan solid), boundary layer process(pink solid), microphysics process (green solid), total flux divergence (thick gray dashed), and total physics (thick gray dotted). The total potential temperature change rate is shown by a thick black solid line, with a smaller-scale axis for this curve labeled along the top of this figure.

(Emanuel et al. 2014), resulting in increased BL density, and a reduction in BL height, which will further result in a horizontal low pressure anomaly right above the BL top. The low pressure anomaly drives a convergent flow and brings mass to the column, resulting in a high pressure BL anomaly while generating $\mathrm{BL}$ divergence and subsidence via continuity. The subsidence brings dry air into the BL, leading to a drying tendency. However, the BL dying tendency increases BL density and pressure and leads to stronger BL divergent flow and subsidence, further drying the BL. A BL dry-subsidence feedback is then revealed.

\section{Discussion and sensitivity experiments}

The fundamental reason for dry patch formation is the establishment of a high pressure anomaly (Naumann et al. 2017; Yang 2018a,b). Both pressure increase in the dry patch and pressure decrease in the wet patch can lead to a high pressure anomaly in dry patch BL. In CNTL, it is quite difficult to find a systematic pressure or density change in the convective regions due to the existence of cold pools. However, it is clear that the pressure and density in the dry patch BL grow systematically over time. The mechanism behind this growth is drysubsidence feedback.

In dry-subsidence feedback, the virtual effect is the key. Only with the virtual effect of dry air can the effect of BL 


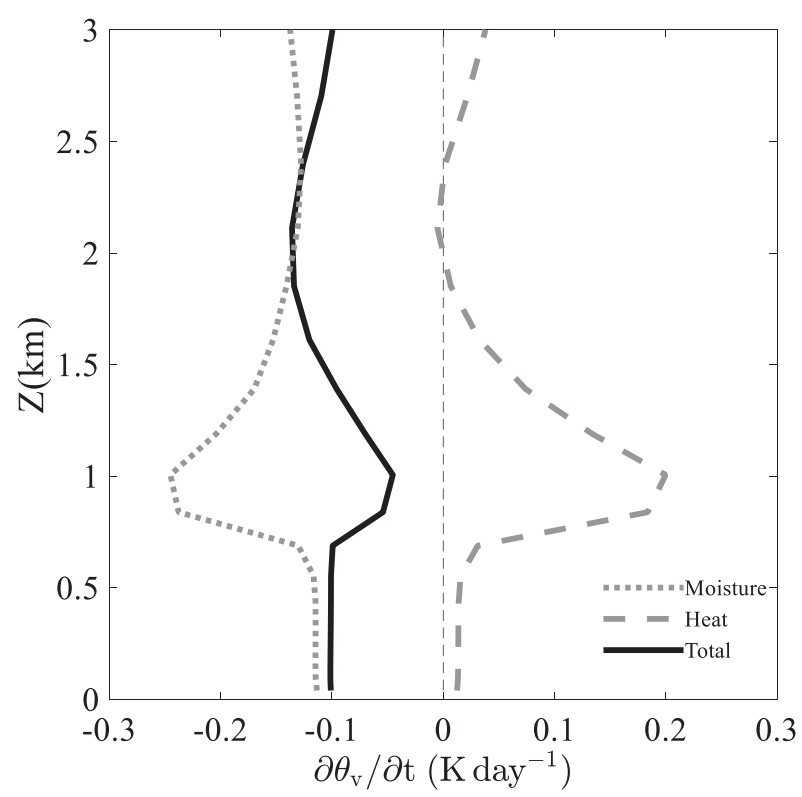

FIG. 11. Vertical profiles of area- and time-averaged (days 10-14) $\partial \theta_{v} / \partial t\left(\mathrm{~K} \mathrm{day}^{-1}\right.$, solid $)$ in the black square shown in Fig. 1 due to contributions from moisture (dotted) and heat (dashed).

warming tendency be counteracted, finally leading to a BL density increase in dry patches. To test the importance of virtual effect, two sensitivity experiments, Virtual_more and Virtual_less, are designed. Virtual_more restarts at 0000 LT on day 8 of CNTL, with dry air molecular weight switched from 29 to $33 \mathrm{~g} \mathrm{~mol}^{-1}$. Virtual_less is the same as Virtual_more, but with dry air molecular weight set to $24 \mathrm{~g} \mathrm{~mol}^{-1}$. Figures $12 \mathrm{a}$ and $12 \mathrm{~b}$ show the WVP averaged on day 15 in Virtual_more and Virtual_less, respectively. The overall WVP in Virtual_more is a little bit lower than in Virtual_less because Virtual_more average temperature is about $2 \mathrm{~K}$ cooler than in Virtual_less. Dry patches in Virtual_more develop faster than in CNTL (Fig. 1c), while dry patches in Virtual_less develop more slowly. Dry patch density increase in Virtual_more is also faster than in Virtual_less (not shown), validating the importance of the virtual effect in dry patch formation. From an APE production perspective, Yang (2018b) also mentioned the importance of the virtual effect (especially in the BL) in convective self-aggregation. On the other hand, strong BL longwave radiative cooling is an important precondition in "dry subsidence" feedback. Strong BL longwave radiative cooling counteracts a large amount of heating by subsidence warming and the BL process, which makes sure that BL drying finally results in a density increase. It is also consistent with previous studies that strong $\mathrm{BL}$ radiative cooling is critical to the formation of dry patches (e.g., Muller and Held 2012; Muller and Bony 2015).

It is noteworthy that the virtual effect is not a necessary condition for dry patch formation. Yang (2018a) also shows that there will still be convective self-aggregation even when the virtual effect is turned off. It is possible to have dry patch formation without the virtual effect as long as dry patch BL corresponds to a cold anomaly, as shown in previous studies (e.g., Coppin and Bony 2015). However, the dry patches correspond to a warm BL anomaly in CNTL. A recent study shows that the BL temperature anomaly of dry patches is sensitive to
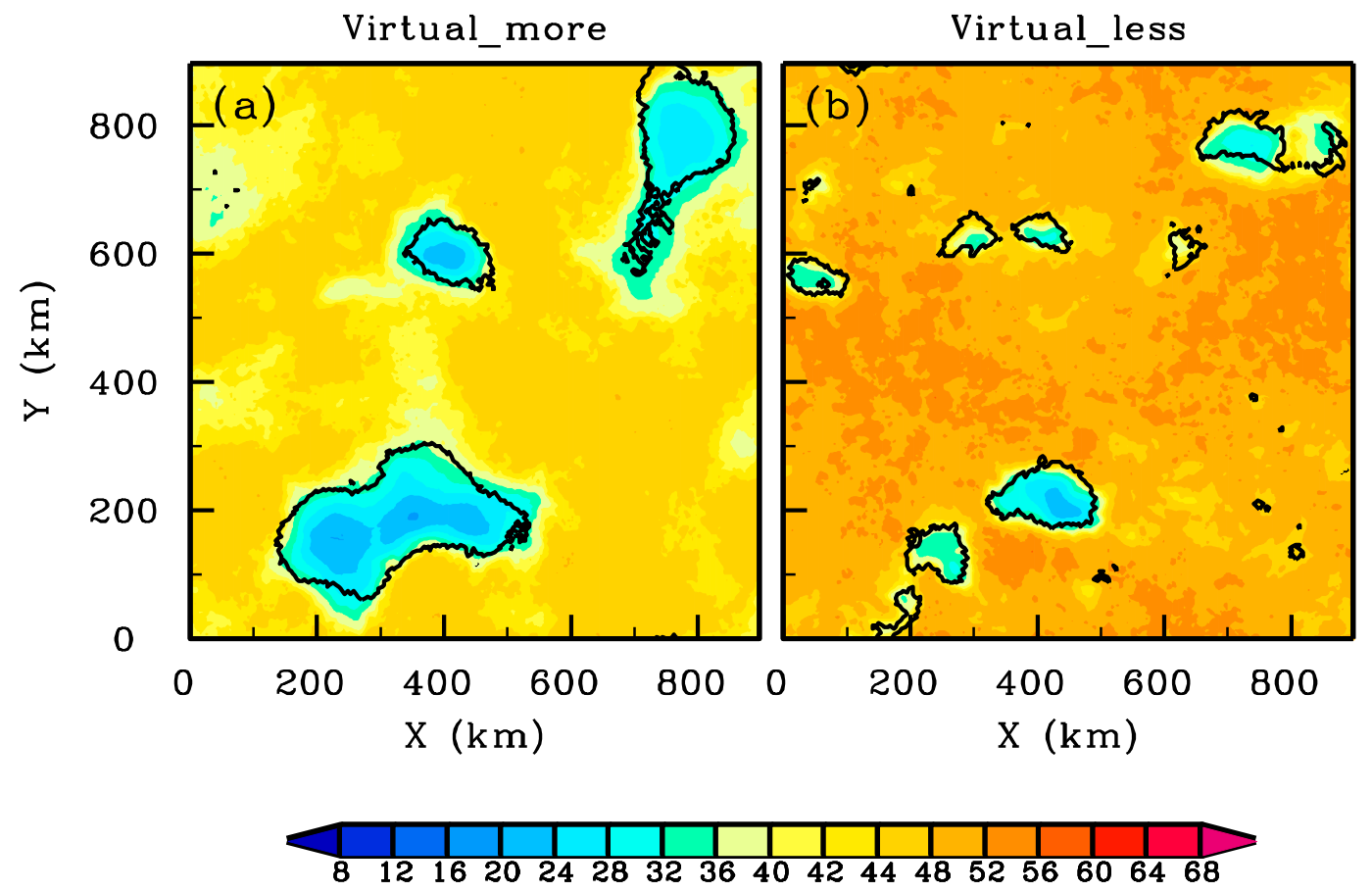

FIG. 12. Daily mean water vapor path $\left(\mathrm{kg} \mathrm{m}^{-2}\right)$ averaged on day 15 in (a) Virtual_more and (b) Virtual_less. The dry patches are marked with black contours. 

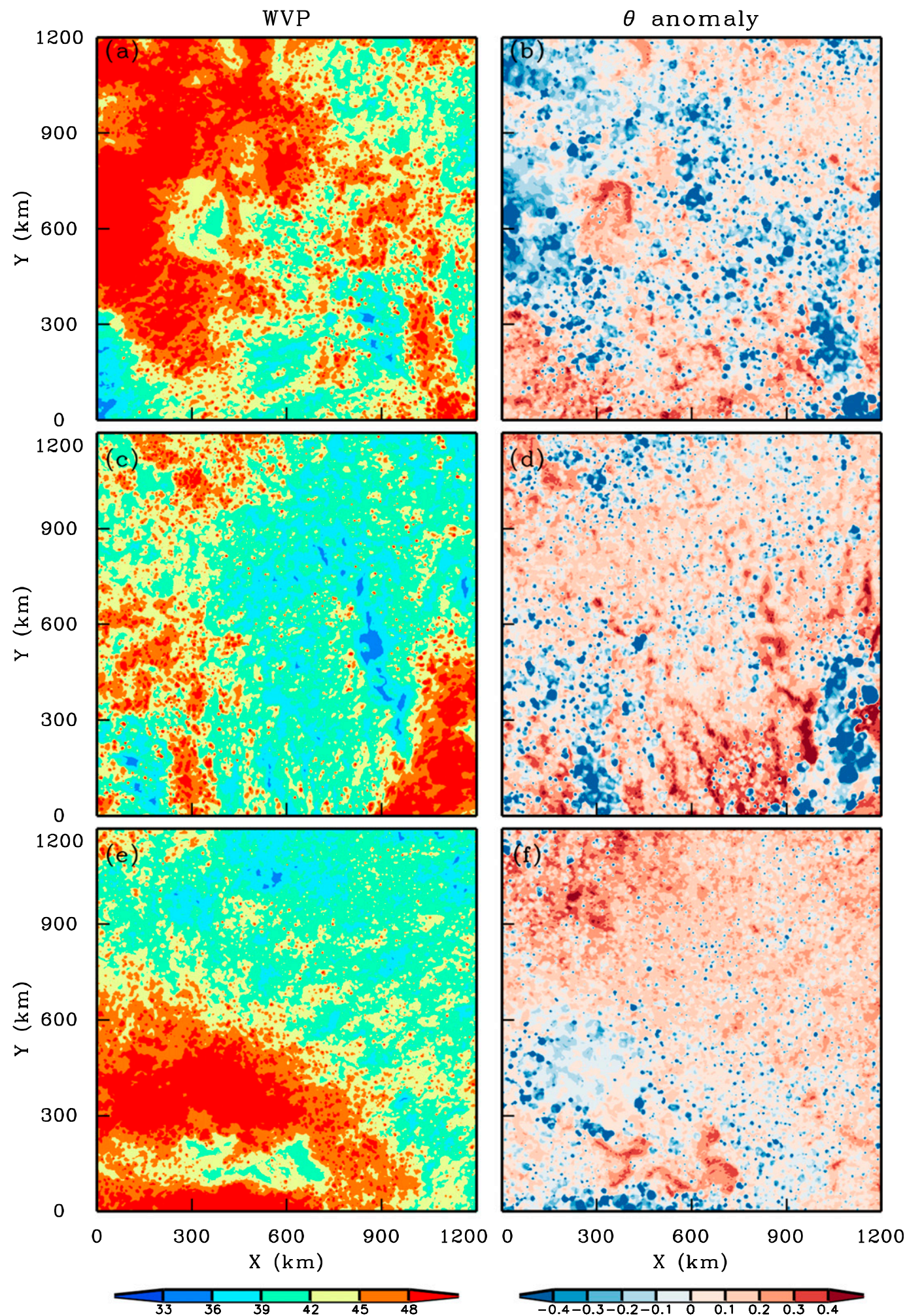

FIG. 13. (a),(c),(e) Water vapor path $\left(\mathrm{kg} \mathrm{m}^{-2}\right)$ in three subareas at 0000 LT on day 8 in CNTL_L. (b),(d),(f) As in (a), (c), and (e), but for the vertically averaged (level 1-7) BL horizontal potential temperature anomaly (K). 
domain size (Patrizio and Randall 2019). When domain size is small (on the order of $1000 \mathrm{~km}$ ), mature stage dry patches are more likely to correspond to a warm BL anomaly. Therefore, the importance of dry-subsidence feedback in large-domain cloud-resolving simulations is worth studying. To verify the importance of dry-subsidence feedback in large domain convective self-aggregation, a simulation CNTL_L is conducted. The model set in CNTL_L is the same as in CNTL, but the domain size is much larger, with the west-east domain length of $9000 \mathrm{~km}$ and the south-north domain length of $3000 \mathrm{~km}$. It is a basin-scale cloud-resolving simulation. In CNTL_L, dry patch formation is much faster than in CNTL. Discernable dry patches are observed after only 6 days. Figure 13 shows three subareas with discernable dry patches at 0000 LT on day 8 with bands and cells observed in these areas. Interestingly, even in a basin-scale simulation, dry patches still correspond to a warm $\mathrm{BL}$ anomaly during the intensification period (in the mature stage, however, dry patches also correspond to a cold BL anomaly in CNTL_L). This indicates that drying caused by subsidence is still necessary to form a high pressure anomaly in dry patches in large domain simulations. Therefore, at least in this particular model and setup, dry-subsidence feedback is critical to the continuous drying of dry patches in cloudresolving convective self-aggregation simulations, irrespective of domain size.

\section{Conclusions}

We use the WRF Model to investigate the mechanisms of dry patches initiation in convective self-aggregation. Generally, the development of dry patches can be separated into two stages. Stage 1 is from day 1 to 14 , during which dry patch intensification dominates, and in stage 2 , from day 14 to 70 , expansion and merging of dry patches dominates. After 70 days, convection finally self-aggregates into a cluster and the system reaches equilibrium. The characteristics of convective self-aggregation and the feedbacks during this process are generally similar to those revealed in previous studies.

Continuous BL drying is critical to the formation of dry patches. Water vapor budget analysis reveals that the BL process, which is related to surface flux, moistens the dry patch BL. Conversely, increasing amounts of dry air is brought down into the BL by an intensifying subsidence at the BL top, which counteracts moistening by the BL process and finally leads to drying in the dry patch BL. Budget analysis of $\theta_{v}$, reveals a boundary layer dry-subsidence feedback where an air density increase leads to an enhanced high pressure anomaly, which drives an amplifying BL divergent flow and induces an amplifying BL subsidence. Subsidence drying counteracts subsidence warming and warming from BL parameterization, which further increases BL air density and pressure. This feedback is shown to be very important for the development of dry patches even in a very large-scale $(3000 \mathrm{~km} \times 9000 \mathrm{~km})$ convective selfaggregation simulation.

Our study focuses on the initiation of dry patches in convective self-aggregation. However, previous studies show that mechanisms for dry patch expansion may be quite different from those for their initiation. The importance of this feedback at different stages is still unclear. On the other hand, when sea surface temperature increases to a certain threshold, wet areas getting wetter might be more obvious in the early stage of convective self-aggregation. The importance of this feedback to the formation of dry patches in different scenarios also requires further investigation.

Acknowledgments. This work is jointly supported by the National Key R\&D Program of China under Grants 2017YFC1501601, the National Natural Science Foundation of China (61827901). The authors thank Bowen Zhou and JianFeng $\mathrm{Gu}$ for useful discussions.

\section{REFERENCES}

Arnold, N. P., and W. M. Putman, 2018: Nonrotating convective selfaggregation in a limited area AGCM. J. Adv. Model. Earth Syst., 10, 1029-1046, https://doi.org/10.1002/2017MS001218.

Beucler, T., and T. W. Cronin, 2016: Moisture-radiative cooling instability. J. Adv. Model. Earth Syst., 8, 1620-1640, https:// doi.org/10.1002/2016MS000763.

$\longrightarrow, \ldots$, and K. A. Emanuel, 2018: A linear response framework for radiative-convective instability. J. Adv. Model. Earth Syst., 10, 1924-1951, https://doi.org/10.1029/2018MS001280.

Bretherton, C. S., P. N. Blossey, and M. Khairoutdinov, 2005: An energy balance analysis of deep convective self-aggregation above uniform SST. J. Atmos. Sci., 62, 4273-4292, https:// doi.org/10.1175/JAS3614.1.

Colin, M., S. Sherwood, O. Geoffroy, S. Bony, and D. Fuchs, 2019: Identifying the sources of convective memory in cloudresolving simulations. J. Atmos. Sci., 76, 947-962, https:// doi.org/10.1175/JAS-D-18-0036.1.

Coppin, D., and S. Bony, 2015: Physical mechanisms controlling the initiation of convective self-aggregation in a general circulation model. J. Adv. Model. Earth Syst., 7, 2060-2078, https://doi.org/10.1002/2015MS000571.

Emanuel, K., A. A. Wing, and E. M. Vincent, 2014: Radiativeconvective instability. J. Adv. Model. Earth Syst., 6, 75-90, https://doi.org/10.1002/2013MS000270.

Grabowski, W. W., and M. W. Moncrieff, 2001: Large-scale organization of tropical convection in two-dimensional explicit numerical simulations. Quart. J. Roy. Meteor. Soc., 127, 445-468, https://doi.org/10.1002/qj.49712757211.

Held, I. M., R. S. Hemler, and V. Ramaswamy, 1993: Radiativeconvective equilibrium with explicit two-dimensional moist convection. J. Atmos. Sci., 50, 3909-3927, https://doi.org/ 10.1175/1520-0469(1993)050<3909:RCEWET>2.0.CO;2.

Holloway, C., and S. Woolnough, 2016: The sensitivity of convective aggregation to diabatic processes in idealized radiativeconvective equilibrium simulations. J. Adv. Model. Earth Syst., 8, 166-195, https://doi.org/10.1002/2015MS000511.

Hong, S. Y., Y. Noh, and J. Dudhia, 2006: A new vertical diffusion package with an explicit treatment of entrainment processes. Mon. Wea. Rev., 134, 2318-2341, https://doi.org/10.1175/ MWR3199.1.

Houze, R. A., Jr., and A. K. Betts, 1981: Convection in GATE. Rev. Geophys. Space Phys., 19, 541-576, https://doi.org/10.1029/ RG019i004p00541.

Iacono, M. J., J. S. Delamere, E. J. Mlawer, M. W. Shephard, S. A. Clough, and W. D. Collins, 2008: Radiative forcing by longlived greenhouse gases: Calculations with the AER radiative transfer models. J. Geophys. Res., 113, D13103, https://doi.org/ 10.1029/2008JD009944. 
Jeevanjee, N., and D. M. Romps, 2013: Convective self-aggregation cold pools, and domain size. Geophys. Res. Lett., 40, 994-998, https://doi.org/10.1002/grl.50204.

Muller, C., and I. M. Held, 2012: Detailed investigation of the self-aggregation of convection in cloud-resolving simulations. J. Atmos. Sci., 69, 2551-2565, https://doi.org/10.1175/ JAS-D-11-0257.1.

why? Geophys. Res. Lett., 42, 5626-5634, https://doi.org/ 10.1002/2015GL064260.

Naumann, A. K., B. Stevens, C. Hohenegger, and J. P. Mellado, 2017: A conceptual model of a shallow circulation induced by prescribed low-level radiative cooling. J. Atmos. Sci., 74, 3129-3144, https://doi.org/10.1175/JAS-D-17-0030.1.

Patrizio, C. R., and D. A. Randall, 2019: Sensitivity of convective self-aggregation to domain size. J. Adv. Model. Earth Syst., 11, 1995-2019, https://doi.org/10.1029/2019MS001672.

Sessions, S. L., M. J. Herman, and S. Sentić, 2015: Convective response to changes in the thermodynamic environment in idealized weak temperature gradient simulations. J. Adv. Model. Earth Syst., 7, 712-738, https://doi.org/10.1002/2015MS000446.

Skamarock, W. C., and Coauthors, 2008: A description of the Advanced Research WRF version 3. NCAR Tech. Note NCAR/TN475+STR, 113 pp., http://doi.org/10.5065/D68S4MVH.

Sobel, A. H., G. Bellon, and J. Bacmeister, 2007: Multiple equilibra in a single-column model of the tropical atmosphere. Geophys. Res. Lett., 34, L22804, https://doi.org/10.1029/2007GL031320.

Stein, T. H. M., C. E. Holloway, I. Tobin, and S. Bony, 2017: Observed relationships between cloud vertical structure and convective aggregation over tropical ocean. J. Climate, 30, 2187-2207, https://doi.org/10.1175/JCLI-D-16-0125.1.

Thompson, G., R. M. Rasmussen, and K. Manning, 2004: Explicit forecasts of winter precipitation using an improved bulk microphysics scheme. Part I: Description and sensitivity analysis. Mon. Wea. Rev., 132, 519-542, https://doi.org/ 10.1175/1520-0493(2004)132<0519:EFOWPU>2.0.CO;2.

Tobin, I., S. Bony, and R. Roca, 2012: Observational evidence for relationships between the degree of aggregation of deep convection, water vapor, surface fluxes, and radiation. J. Climate, 25, 6885-6904, https://doi.org/10.1175/JCLI-D-11-00258.1.

Tompkins, A. M., 2001: Organization of tropical convection in low vertical wind shears: The role of water vapor. J. Atmos. Sci., 58, 529-545, https://doi.org/10.1175/1520-0469(2001)058<0529: OOTCIL $>2.0 . C O ; 2$.

__ , and G. C. Craig, 1998: Radiative-convective equilibrium in a three-dimensional cloud-ensemble model. Quart. J. Roy. Meteor. Soc., 124, 2073-2097, https://doi.org/10.1002/ qj. 49712455013 .

— tion in low vertical wind shears: Role of updraft entrainment. J. Adv. Model. Earth Syst., 9, 1046-1068, https:// doi.org/10.1002/2016MS000802.

Wing, A. A., and K. A. Emanuel, 2014: Physical mechanisms controlling self-aggregation of convection in idealized numerical modeling simulations. J. Adv. Model. Earth Syst., 6, 59-74, https://doi.org/10.1002/2013MS000269.

_- K. Emanuel, C. E. Holloway, and C. Muller, 2017: Convective self-aggregation in numerical simulations: A review. Surv. Geophys., 38, 1173-1197, https://doi.org/ 10.1007/s10712-017-9408-4

Yang, D., 2018a: Boundary layer height and buoyancy determine the horizontal scale of convective self-aggregation. J. Atmos. Sci., 75, 469-478, https://doi.org/10.1175/JAS-D-17-0150.1.

- 2018b: Boundary-layer diabatic processes, the virtual effect, and convective self-aggregation. J. Adv. Model. Earth Syst., 10, 2163-2176, https://doi.org/10.1029/2017MS001261. 